\title{
Expertise-related differences in conceptual and ontological knowledge in the legal domain.
}

Citation for published version (APA):

Nievelstein, F., Van Gog, T., Boshuizen, E., \& Prins, F. (2008). Expertise-related differences in conceptual and ontological knowledge in the legal domain. European Journal of Cognitive Psychology, 20(6), 1043-1064.

https://doi.org/10.1080/09541440701674777

DOI:

$10.1080 / 09541440701674777$

Document status and date:

Published: $17 / 10 / 2008$

Document Version:

Peer reviewed version

Please check the document version of this publication:

- A submitted manuscript is the version of the article upon submission and before peer-review. There can be important differences between the submitted version and the official published version of record. People interested in the research are advised to contact the author for the final version of the publication, or visit the DOI to the publisher's website.

- The final author version and the galley proof are versions of the publication after peer review.

- The final published version features the final layout of the paper including the volume, issue and page numbers.

Link to publication

\section{General rights}

Copyright and moral rights for the publications made accessible in the public portal are retained by the authors and/or other copyright owners and it is a condition of accessing publications that users recognise and abide by the legal requirements associated with these rights.

- Users may download and print one copy of any publication from the public portal for the purpose of private study or research.

- You may not further distribute the material or use it for any profit-making activity or commercial gain

- You may freely distribute the URL identifying the publication in the public portal.

If the publication is distributed under the terms of Article 25fa of the Dutch Copyright Act, indicated by the "Taverne" license above, please follow below link for the End User Agreement:

https://www.ou.nl/taverne-agreement

Take down policy

If you believe that this document breaches copyright please contact us at:

pure-support@ou.nl

providing details and we will investigate your claim.

Downloaded from https://research.ou.nl/ on date: 26 Apr. 2023 
Running head: CONCEPTUAL KNOWLEDGE DIFFERENCES

This is a pre-print of: Nievelstein, F., Van Gog, T., Boshuizen, H. P. A., \& Prins, F. J. (2008). Expertise-related differences in conceptual and ontological knowledge in the legal domain. European Journal of Cognitive Psychology, 20, 1043-1064.

Copyright Taylor \& Francis; European Journal of Cognitive Psychology is available online at http://www.tandf.co.uk/journals/pp/09541446.html

Expertise-Related Differences in Conceptual and Ontological Knowledge in the Legal Domain Fleurie Nievelstein ${ }^{\mathrm{a}, *}$, Tamara van Gog ${ }^{\mathrm{a}}$, Henny P. A. Boshuizen ${ }^{\mathrm{a}}$ and Frans J. Prins ${ }^{\mathrm{a}}$ b

${ }^{a}$ Educational Technology Expertise Centre, Open University of the Netherlands, Heerlen, The Netherlands

${ }^{\mathrm{b}}$ Department of Pedagogical and Educational Sciences, Utrecht University, Utrecht, The Netherlands

* Correspondence concerning this article should be addressed to Fleurie Nievelstein, Open University of the Netherlands, Educational Technology Expertise Center, P.O. Box 2960, 6401 DL, Heerlen, The Netherlands. T: +31 45 5762842; F: +31 45 5762907; E: fleurie.nievelstein@ou.nl Acknowledgements

We would like to thank LL.M. Peter Slangen for his judicial input and Dr. Lars van Vliet for the practical facilitation of this study. 


\begin{abstract}
Little research has been conducted on expertise-related differences in conceptual and ontological knowledge in law, even though this type of knowledge is prerequisite for correctly interpreting and reasoning about legal cases, and differences in conceptual and ontological knowledge structures between students and between students and teachers, might lead to miscommunication. This study investigated the extent and organization of conceptual and ontological knowledge of novices, advanced students, and experts in law, using a card-sorting task and a conceptelaboration task. The results showed that novices used more everyday examples and were less accurate in their elaborations of concepts than advanced students and experts, on top of that, the organization of their knowledge did not overlap within their group (i.e., no "shared" ontology). Experts gave more judicial examples based on the lawbook and were more accurate in their elaborations than advanced students, and their knowledge was strongly overlapping within their group (i.e., strong ontology). Incorrect conceptual knowledge seems to impede the correct understanding of cases and the correct application of precise and formal rules in law.
\end{abstract}


Expertise-Related Differences in Conceptual and Ontological Knowledge in the Legal Domain

A large body of research on the amount and structure of knowledge of individuals with different levels of expertise exists in various academic and professional domains such as medicine, management, counseling and physics (see Chi, Glaser, \& Farr, 1988; Ericsson, Charness, Feltovich, \& Hoffman 2006). Conclusions that have been drawn from those studies are mostly formulated in terms of generalities across domains, which might suggest that they are universally valid. However, there are also large differences between domains and between specializations within domains in terms of the quality and the structure of expert knowledge, which makes it worthwhile to study expertise differences in different domains. For example, Elstein (2001), reviews evidence that, the nature of expertise in the medical domain varies among the different specializations. Hunt (2006) has shown that expertise in a specific domain is characterized by specialized domain knowledge and specific (cognitive) skills which do not transfer to performing tasks in other domains.

Research on knowledge structures and knowledge differences in the domain of law is scarce, which is surprising given that the legal domain has some unique characteristics that make it difficult to learn and master (Nievelstein, Van Gog, \& Prins, in press; Sullivan, Colby, WelchWegner, Bond, \& Shulman, 2007). First of al, novices in law must familiarize themselves with the "official" use of legal language. This can be difficult, because many concepts that are routinely used in everyday language often have a very specific formal meaning in law (Lindahl, 2004). A second difficulty of the legal domain is that certain concepts (i.e, intermediate concepts) are not confined to one single, fixed meaning. In two different legal situations, those intermediate concepts could have a different meaning depending on the exact situational context (Ashley \& Aleven, 1991; Lindahl, 2003; for an example see the section below on "the role of conceptual knowledge and ontology in law"). Another characteristic of the legal domain is that it is 
adversarial in nature, that is, it requires students to learn to take multiple perspectives on the same legal problem (e.g., lawyer, prosecutor, judge). From a certain perspective one should act in a certain way to achieve the obtained goal, but one will only be successful in doing so when possible (counter)arguments of the opposite party are taken into account.

Conceptual and ontological knowledge plays a key role in law: It is prerequisite for correctly interpreting and reasoning about legal cases, and differences in conceptual and ontological knowledge structures between students themselves and between students and teachers, might lead to miscommunication about legal rules and cases. The term 'conceptual knowledge' refers to an individual's entire knowledge base of concepts and relations between concepts, which can be either formally correct or incorrect (Roth, 1990); two people can assign different meanings to the concept society, for example. The term ontology, in its philosophical definition, refers to the conceptual knowledge regarding basic categories of existence in life such as plants, animals and objects (see e.g., Kelly \& Keil, 1985) and implies knowledge about the features and underlying principles of those basic categories. Nowadays, the term ontology is often used in the domain of artificial intelligence, where it is defined as a formalized conceptual vocabulary that can be seen as a shared and agreed upon, explicit representation of a domain (Bench-Capon \& Visser, 1997; Chi \& Roscoe, 2002; Visser \& Bench-Capon, 1998), which is the definition we will use here. A cardiologist, for example, should have formal conceptual knowledge about the functioning of the heart. This formal conceptual knowledge can be referred to as a part of the cardiologist's ontology. In sum, ontological knowledge is conceptual knowledge that corresponds to the underlying structure or organization of the domain, and hence, correct conceptual domain knowledge should be acquired before a domain's ontology can be mastered (see e.g., Chi \& Roscoe, 2002).

Correct conceptual and ontological knowledge are important for two main reasons. It is 
required for correct classification of problems and tasks one encounters (Chi, 2005; Roth, 1990), and it is essential that individuals working or studying in the same domain to have a similar understanding of concepts in order to communicate precisely and without misunderstanding about domain-related problems (Klausmeister, 1990). Therefore, studies of how conceptual and ontological knowledge is acquired are important. Not only can they provide interesting information on an important part (i.e., the knowledge base) of participants with different levels of expertise in a domain, but such studies can also ultimately contribute to our understanding of difficulties students experience and the development of (educational) support for expertise acquisition in these domains (see e.g., Boshuizen \& Schmidt, 1992; Chi, 2005).

Most studies on law expertise have been conducted in the context of artificial intelligence and the development of legal knowledge systems (Ashley \& Brüninghaus, 2003; Bench-Capon \& Visser, 1997; Visser \& Bench-Capon, 1998). However, as in the context of expertise research, the question of how conceptual and ontological knowledge differs between participants with different levels of expertise in the legal domain, has not received much attention in the AI context either.

Therefore, the present study investigates expertise-related differences in conceptual knowledge structures and ontology in law. Expertise in the legal domain is interesting to study because it has some intrinsic characteristics that make it a difficult domain to learn and to master (Nievelstein, et al., 2007), to which we will return below. First, we will discuss research on conceptual knowledge structures in some more detail.

\section{Conceptual Knowledge Structures}

Findings from research on expertise differences suggest that experts in a domain have acquired elaborate mental frameworks or schemata that allow them to effectively and efficiently interpret information or problems that they are confronted with. Schemata contain both declarative and procedural knowledge (Chi, 2005; Dufresne, Gerace, Thibodeau-Hardiman, \& 
Mestre, 1992; Schank \& Abelson, 1977). When a task or problem, for which a schema has been acquired, is encountered, the schema will be activated. As a result, the problem is classified as belonging to a certain category and an associated solution procedure is activated with varying degrees of automation depending on the quality of the schema (Anderson, Reynolds, Schallert, \& Goetz, 1977). Dufresne et al. (1992) suggested that domain-specific knowledge of experts is hierarchically organized in schemata. If experts are confronted with a domain-related problem, a hierarchical, tree-like schema with a top-down problem solving approach including domain concepts and procedures will be activated. Depending on the context and the problem at hand, a specific schema will be activated. The meaning of an activated schema is derived from the kind, the position and the relation between the activated nodes in the schema (Chi, 1997). Novices' problem schemata seem to consist of loosely linked, incomplete, and sometimes incorrect knowledge. Therefore, novices' schemata are less easily activated, and when these schemas are activated, they support problem solving to a lesser extent than experts' schemata do (Boshuizen \& Schmidt, 2000; Dufresne et al., 1992).

\section{The Role of Conceptual Knowledge and Ontology in Law}

An important characteristic of the legal profession is that it is very strict about interpreting and relating law concepts. Legal concepts are most important in the profession to interpret and apply legal rules and jurisprudence in a proper way. A difficulty that arises here is that many concepts in law (such as 'demand' or 'verdict') that students know from everyday discourse have a different professional significance (Lindahl, 2004). A similar difficulty is known to arise in physics, where concepts such as electricity and blood flow, which are known from everyday use, have a different, formal meaning that may only partially coincide with the everyday meaning (Chi \& Roscoe, 2002). Everyday knowledge about concepts should be altered into judicial conceptual knowledge, that is, agreed upon between individuals working in the domain (i.e., 
ontology). On top of that, some concepts function as 'intermediate' concepts, which means that they are flexibly interpretable and their exact meaning is determined by specific situational constraints. Depending on the legal situation (the facts) the interpretation of the intermediate concept will differ, as a result of which the legal consequences differ as well (Lindahl, 2003). For example, the legal situation about one's ownership of a specific amount of money received by inheritance, differs from the legal situation about one's ownership of a bike received as a birthday present from a friend. In the first situation the 'ownership' brings along the duty to pay inheritance taxes, whereas in the second situation becoming an owner of a bike by a gift does not oblige the owner to pay any taxes. So the specific context determines the obtained rights and responsibilities the intermediate concept 'ownership' brings along.

Chi (2005) showed that in physics, concepts could be classified in fixed ontological categories, such as the category of kinematics or the category of flow processes. This is not the case with law concepts. This is on the one hand related to the phenomenon of intermediate concepts, and on the other hand to the fact that problem solving and reasoning in law is often adversarial, that is, performed in a context of debate and disagreement, which requires that one must learn to take multiple perspectives in order to anticipate on counterarguments and exceptions (Thagard, 1992). Despite the strict definitions of legal concepts, it is important that concepts can be flexibly applied in distinctive situations.

\section{Uncovering Expertise-Related Differences in Conceptual Knowledge Structures}

The present study investigates differences in the structure and content of conceptual knowledge between novices, advanced students, and experts in civil law, using a card-sorting task (De Jong \& Ferguson-Hessler, 1986; Trochim, 1989), which requires participants to group (relate) a certain number of given concepts (printed on cards), and a concept elaboration task (Van de Wiel, Boshuizen, \& Schmidt, 2000; Van de Wiel, Boshuizen, Schmidt, \& Schaper, 
1999), which requires participants to verbalize everything they know about a concept in a short time frame (e.g., 2 or 3 minutes).

Card-sorting tasks provide insight into differences in the organization of conceptual knowledge of individuals at different levels of expertise. Because card-sorting tasks do not require students to draw or label links between concepts, however, a concurrent verbal reporting technique will be applied in this study to gather information on why certain concepts are clustered together (cf. Ericsson \& Simon, 1993; Van Gog, Paas, Van Merriënboer, \& Witte, 2005). Concept-elaboration tasks provide insight into expertise differences in the depth of knowledge about concepts and about associations with other concepts that are spontaneously reported.

Based on previous research that addressed expertise-related differences in conceptual knowledge and ontology using comparable techniques (e.g., Boshuizen \& Schmidt, 1992; Van de Wiel, et al., 2000) it is expected that experts' knowledge is not only more elaborate and accurate, but also more structured and organized than students' knowledge. This would show, for example, in experts providing more central concepts around which they structurally group other concepts in the card-sorting task, than advanced students and novices, who are likely to sort concepts in a less organized, unconnected way. Based on previous research on concept knowledge and elaboration (e.g., Chi \& Roscoe, 2002; Van de Wiel, et al., 1999), it is expected that novices will have misconceptions about the formal meaning of legal concepts. This might lead novices to provide more daily examples instead of giving the formal legal meaning in elaborating on legal concepts, because novices only know the concepts from daily life. Moreover, experts could be expected to provide more accurate, formal concept elaborations (and as a result show more overlap -indicative of ontology- with other experts in their card sorting as well) than novice and advanced students. 
Specifically, this study investigates expertise-related differences in conceptual knowledge and ontology in the legal domain. It is hypothesized that: 1) As expertise increases, knowledge would be more hierarchically structured and show more overlap with individuals of the same level of expertise, 2) more central concepts would be provided in the card sorting task as expertise increases, 3) novices would order concepts randomly (without any structure) more often than advanced students and experts, 4) concept elaborations would be more accurate as expertise increases (which implies a higher degree of overlapping knowledge and agreed upon explicit representations, i.e., ontology), and 5) novices will give more daily examples in their elaborations than advanced students and experts.

\section{Method}

\section{Participants}

In total, 48 students involved in civil law courses (Dutch specification: 'privaatrecht') and 12 staff members specialized in civil law (Dutch specification: 'privaatrecht') from law schools of Dutch universities participated in this study. They were 24 first-year students (novice group), 24 third-year students (advanced group), and 12 staff members of the faculty of law with on average 5.9 years of professional experience after obtaining their PhD (expert group). Students received a financial compensation of $€ 10$ for their participation.

\section{Materials}

Audio recording equipment. Verbalizations were recorded on a laptop computer with Audacity 1.2.4b audio editor (http://audacity.sourceforge.net) using a microphone.

Card-sorting task. The card-sorting task consisted of 30 different concepts, printed on separate cards, that were all in some way related to one main concept in civil law: 'tort'. All concepts were derived from the index of the lawbook (cf. Crombag, de Wijkersloot, \& Cohen, 1977). 
Concept-elaboration task. The concept-elaboration task consisted of three central concepts (strict liability, damages, tort/unlawful act), one abstract concept (protective norm), and one intermediate concept (owner), selected from the concepts in the card-sorting task. These concepts were identified as central, abstract and intermediate based on the lawbook, and this was verified by a domain expert. The central concepts are concrete terms: the tort itself, one condition, and one consequence of the tort. The abstract concept is an abstract term that is indirectly related to the main concept 'tort'. Finally the intermediate concept can be interpreted in several ways depending on the situation that is characterized. The five concepts were printed on separate cards.

\section{Procedure}

Individual sessions of approximately 40 minutes were scheduled at the law schools. Participants first completed the card-sorting task. They were instructed to group the 30 civil law concepts in such a way that the concepts in one group had stronger relations with each other than with concepts sorted in another group. No prompts were given as to how many clusters to create. Participants were asked to verbalize aloud why they put specific concepts together and how these concepts were related to each other, and were instructed to ignore the presence of the experimenter in doing so. Participants then completed the concept-elaboration task. They received the five concepts one by one in random order, and were instructed to verbalize everything they knew about that specific concept, in a fixed time of two minutes per concept. After each individual session, a debriefing took place in which the experimenter asked participants how they felt about the session and provided information about the goal of the study. Data Analysis

The card-sorting task was analysed by means of a hierarchical cluster analysis (cf. De Jong \& Ferguson-Hessler, 1986; Trochim, 1989) of unstructured card sort data in SPSS, version 
12.0.1. Cluster analysis calculates the strength of the perceived relationships between concepts, and graphically displays these relationships in dendrograms. Each participant's sorting was represented into a $30 \times 30$ symmetrical matrix, where clustered concepts are represented by 1 and not-clustered concepts by 0 . Per group a total similarity matrix was calculated by summing all individual matrices. In the dendrogram, the sub-clusters are listed along the y-axis. The x-axis determines the cluster distance: The smaller the distance (farthest left), the greater the proximity between concepts.

To study the structure of the conceptual knowledge in detail, the total number of clusters participants had made upon completing the task was counted by the experimenter, and based on participants' transcribed verbal protocols it was scored whether the content of every single pile was composed around one central concept or consisted of a string of unconnected concepts. However, it became apparent during data analysis that participants also labelled clusters as belonging to specific fields of law and mentioned specific concepts as 'top concept' to which all clusters could be connected. A top concept differed from a central concept in that it connected all single clusters with each other, whereas a central concept only connected concepts within one cluster.

Coding scheme. For the concept-elaboration task a coding scheme was developed based on concept descriptions in the civil lawbook (Klomp \& Mak, 2005) and based on several kinds of examples. Every 'model' description of a concept in the lawbook was divided into single elements, which resulted in 10 elements for 'tort', 2 for 'strict liability', 4 for 'damages', 1 for 'protective norm' and 1 for 'owner'. The number of the protocol elements that matched the elements of the 'model' description were counted. Information that was exactly repeated in an elaboration was only counted once (e.g., if the same lawbook element was mentioned twice or if the same example was given twice, the second time was not counted). The coding scheme is 
shown in the Appendix. First, parts of the protocol that corresponded to a lawbook element were scored. Second, given examples in the protocol were scored. Three types of examples were distinguished: 1) daily examples not related to an element of the concept description in the lawbook, 2) judicial examples not related to an element of the lawbook, and 3) judicial examples related to an element of the lawbook.

Two raters independently scored $20 \%$ of the protocols. The inter-rater reliability was .78 (Cohen's kappa). Because the inter-rater reliability was sufficiently high (i.e., higher than .70; Van Someren, Barnard, \& Sandberg, 1994), the remaining protocols were scored by one rater. For the analyses we only used the scores of the rater who scored all protocols.

\section{Results}

\section{Card sorting task}

To address the first hypothesis that more expertise leads to more hierarchically structured knowledge, hierarchical cluster analyses were performed on the data of each group. The resulting dendrograms are shown in Figures 1, 2, and 3. The results of the cluster analyses illustrated that novices show no specific pattern in the way they clustered the concepts. Their clustering was mainly based on connecting two or three concepts that have a basic 'cause-consequence' relationship. Examples are, the clusters 'owner'-'ownership' and 'injury'- 'emotional damage'. However, these relationships were not embedded in meaningful clusters. The dendrogram of the advanced students showed that the first and the second strong clusters (proximity level $<0.7$ ) were related with each other at the proximity level of 0.3 . Only concepts related to the tenet 'tort' were strongly clustered together. The related concepts reflected the five conditions of a 'tort': 'damage' (and its specific types of damage and damages), 'causality', 'liability and 'protective norm'. One other strong cluster was made up of the concepts 'owner', 'ownership', and 'object'. These concepts are central to the field of 'property law'. The experts' dendrogram reflected an 
obvious division between one cluster about the field of 'patrimonial law' (concepts 12 to 20 vertically) in general on the one hand and a specific split between one cluster about the field of 'property law' (concepts 8 to 23 vertically) and one cluster about the field of 'law of obligations'(concepts 26 to 22 vertically). This conceptual division corresponded to a detailed 'fields of law' description in a key textbook on Dutch civil law (Boon, Reijntjes, \& Rinkes, 2003). In this chapter, important concepts for the different fields are stressed. For example, the concepts owner, ownership and object are stressed as important terms in the field of "property law'.

To test the second and third hypotheses that experts would provide more central concepts to build their clusters than novices and advanced students, and that novices will create clusters far more often based on randomly ordered concepts than advanced students and experts, the protocol data were analysed. The number of times participants created their clusters around central concepts or constructed clusters with unconnected strings of concepts was analysed by means of ANOVA (significance level set at .05) with level of expertise as independent variable. No differences were found between groups in the number of clusters they made $F(2,57)=2.39$, $n s$. Each group made 7 clusters on average. Table 1 shows the mean number of times participants created clusters a) around central concepts, b) based on randomly ordered, unconnected concepts, c) based on fields of law and d) under top concepts. A one-way ANOVA showed a significant effect of level of expertise for the four types of clusters: clusters created around one 'central concept' $F(2,57)=10.14, M S E=2.26, p<.001, f=.60$, clusters that consist of 'unconnected concepts' $F(2,57)=12.27, M S E=5.40, p<.001, f=.66$, clusters composed around 'fields of law' $F(2,57)=25.78, M S E=.43, p<.001, f=.95$, and clusters linked to one 'top concept' $F(2$, $57)=8.76, M S E=.12, p<.001, f=.55$. Bonferroni post-hoc tests (significance level .05) showed that experts mentioned significantly more central concepts, more fields of law and more top 
concepts while composing the clusters, than both novices and advanced students. Furthermore, it was shown that novices ordered their concept clusters significantly more often on a random basis than advanced students and experts.

\section{Concept-elaboration task}

Table 2 shows the means for the elements mentioned accurately with regard to the model description. We hypothesized that with increasing levels of law expertise accuracy of concept elaborations would increase (hypothesis 4). A one-way ANOVA showed a significant effect of expertise on accuracy of all five concepts together $F(2,57)=17.00, M S E=4.96, p<.001, f=$. 77. This significant effect is also found regarding the accuracy of the five concepts separately: 'strict liability' $F(2,57)=12.98 M S E=.28, p<.001, f=.67$, 'tort/unlawful act' $F(2,57)=$ $6.45, M S E=3.19 p<.01, f=.48$, 'damages' $F(2,57)=3.60 M S E=.62, p<.05, f=$. 36 , 'protective norm' $F(2,57)=17.90, M S E=.16, p<.001, f=.79$, and 'owner' $F(2,57)=$ $15.44, M S E=.17, p<.001, f=.74$. Bonferroni post-hoc tests showed that in line with our hypothesis, experts were significantly more accurate in elaborating on the three central concepts than the advanced students, and that, surprisingly, novices were significantly more accurate in elaborating on one central concept, the 'tort', than advanced students. Furthermore, in line with our hypothesis, experts were significantly more accurate than novices and advanced students in elaborating on the abstract concept and experts and advanced students were both more accurate in elaborating on the intermediate concepts than novices. Because intermediate concepts can have a different meaning depending on the exact situational context, this finding suggests that increasing expertise is characterized by the ability to flexibly activate different schemata with regard to a single judicial concept.

Because we expected novices in the domain of civil law to know domain-related concepts from everyday discourse instead of legal definitions, we hypothesized that they would provide 
more examples in their explanations than advanced students and experts. The number of examples given in the concept-elaboration task were counted, and three types of examples were distinguished. Table 3 shows the mean number of daily examples (i.e., not related to elements of the lawbook; Type 1), judicial examples not related to elements of the lawbook (Type 2), and judicial examples related to elements of the lawbook (Type 3) given in the concept-elaboration task. A one-way ANOVA on expertise differences regarding Type 1 examples for the five concepts shows a significant expertise effect $F(2,57)=227.56, M S E=1.75, p<.001, f=2.83$. Bonferroni post-hoc tests showed that novices use significantly more daily examples in their concept elaborations than advanced students and experts. Significant differences between groups were also found in the number of Type 2 examples given, $F(2,57)=6.99, M S E=.21, p<.01, f$ $=.49$. Novices gave significantly more judicial examples which were not related to the elements of the lawbook concerning the concept content. A one-way ANOVA on expertise differences in Type 3 examples showed a significant expertise effect $F(2,57)=20.93, M S E=8.02, p<.001, f$ $=.86$. Bonferroni post-hoc tests showed that as expertise develops, participants will use significantly more Type 3 examples in their elaborations. In other words, advanced students used significantly more Type 3 examples than novices whereas experts used significantly more Type 3 examples than advanced students. The data in the table show that experts gave most Type 3 examples, on average, for the intermediate concept 'owner', whereas novices gave most Type 3 examples, on average, for the three central concepts 'strict liability', 'damages' and 'tort'.

\section{Discussion}

This study investigated how acquired conceptual knowledge structures differ between novices, advanced students and experts. We hypothesized that 1) knowledge would become more hierarchically structured and would show more overlap as expertise increases, 2) more central concepts would be provided in the card sorting task as expertise increases, 3) novices would 
order concepts more often randomly than advanced students and experts, 4) concepts elaborations would be more accurate as expertise increases and, 5) novices will give more examples in their elaborations than advanced students and experts. The results of the hierarchical cluster analyses and verbal protocol analyses support our hypotheses that knowledge becomes more hierarchically structured with increasing expertise. It was shown that experts used the same central concepts to create clusters, embedded in specific fields of law with connections to single top concepts. For advanced students, only their knowledge regarding the tenet 'tort' was hierarchically structured and overlapping, the other concepts were not yet strongly connected nor structured in a hierarchical whole. Novices' knowledge seemed highly fragmented, they strung concepts together while hardly reporting any meaningful connections between concepts, and their clusters were highly idiosyncratic.

These findings suggest that conceptual knowledge networks of novices in the same domain are very different from each other. In other words, even though students are enrolled in the same curriculum, there is no indication of overlapping knowledge (i.e., mastery of ontology) in the very first stage of legal expertise development. However, individuals at a high expertise level have a more similar knowledge base than individuals at lower expertise levels. Furthermore, these findings suggest that with developing expertise in law, knowledge about concepts and the relations between concepts will gradually become hierarchically structured (e.g., third year students' showed hierarchical and overlapping knowledge of 'tort' but not of the other concepts), and eventually, at the expert level, will also be clustered according to different fields of law (a very high level in the hierarchy).

In addition, our hypothesis was supported that experts would be more accurate in elaborating on legal concepts in formal language than novices and advanced students. Unexpectedly, however, novices were more accurate in defining the concept 'tort' than advanced 
students. A possible explanation for this finding is suggested by the remark of some of the first year students during the debriefing that they had just finished a course component about the tenet tort with an exam, so it is plausible that novices knew the definitions by heart at that moment. With regard to our hypothesis that novices would use more daily examples in their elaborations, the results indeed indicate that novices use a lot of everyday language and daily examples in elaborating on legal concepts. Advanced students used fewer daily examples on average than novices but still significantly more than experts. Furthermore, we found that experts gave most judicial examples for the concept 'owner'. The hierarchical knowledge structure of experts might explain their ability to flexibly and contextually interpret this intermediate legal concepts (compared to the central and abstract concepts). When experts are confronted with an intermediate concept they are able to interpret the concept differently depending on the situated context; a different context activates a different schema.

The results of the cluster analysis and accuracy of elaborations provide indications of ontological differences. It seems that novices have not yet acquired any formal and overlapping explicit judicial representation of these concepts and the domain, which may explain why they heavily rely on their everyday conceptual knowledge. As expertise increases, conceptual knowledge changes into formal knowledge of the domain, which becomes strongly overlapping among experts, indicated by experts' agreement about the kind of concepts reflected in meaningful clusters in the cluster analyses and higher accuracy of their concept elaborations.

This study has some limitations. For instance, we distinguished expertise levels based on years of enrolment, rather than on a pre-test of task or domain specific knowledge. Large withingroup expertise differences are unlikely, because the novices were in their first year and had just started, whereas the advanced students were in their third year and had completed half of the curriculum, and because law is not a subject taught in secondary education or encountered easily 
in extracurricular activities. However, it is possible that some novices have had some prior experience with law before entering the university, or that some third-year students gained less knowledge than their peers during these years of study, making them more similar to novices. A task-specific pre-test (or rapid pre-test; cf. Kalyuga, 2006) would have allowed detection of such possible, though unlikely, exceptions. A related issue concerns the content of the curriculum and the task. The findings regarding the novices' accuracy of elaborations of the concept 'tort' show that certain deviations in results may arise as a consequence of the particular information just provided in the curriculum. A task-specific pre-test could also be used to obtain information about specific differences in prior knowledge within and between groups as a consequence of the curriculum.

As for theoretical relevance of this study, because there are large differences between domains and between specializations within domains in terms of the quality and the structure of expert knowledge, it is worthwhile to study expertise differences in different domains. Some of our findings correspond to those of expertise research in other professional domains, for example that increasing expertise leads to hierarchically structured knowledge (cf. Dufresne et al., 1992; Van de Wiel et al., 2000). Other findings, however, seem to be related to unique characteristics of the legal domain, for example, that the ability to flexibly interpret intermediate legal concepts, depending on the described legal situation, increases with increasing expertise.

Knowledge is a key aspect, but not the sole aspect of expertise (see Ericsson et al., 2006). Thus, future research should also look into how differences in conceptual knowledge influence the ability to reason about legal cases, in order to obtain a more comprehensive picture of expertise acquisition in the legal domain. Another interesting future study would be to use a longitudinal design to investigate how conceptual knowledge develops with increasing expertise, because the cross-sectional design we used here allowed the investigation of expertise-related 
differences in conceptual knowledge at certain stages of expertise, but does not allow conclusions on how these differences came about.

Regarding practical relevance, conceptual and ontological knowledge is very important for the correct classification of problems and tasks, as well as for communication in the domain. Moreover, conceptual knowledge is of pivotal importance for legal skills such as reasoning, defending cases from different points of view (e.g., judge, public prosecutor) and taking into account possible actions of the opposition. Hence, studies such as this one not only foster our insight in domain-specific knowledge of participants at different levels of expertise, but can also provide a starting point for more applied future research on how to facilitate knowledge and skill acquisition, as well as communication in the domain. First of all, future studies could develop and study the effects of different kinds of educational support tools. The instruction students nowadays receive in order to learn to argue on cases is mainly by arguing on cases itself. Given the important role conceptual and ontological knowledge plays in this skill, and given that novice students lack this kind of knowledge, this form of instruction might become more effective when additional support is provided (e.g., worked-out examples, process worksheets). Secondly, future research might look into communication processes. Lack of overlapping knowledge (ontology) might complicate communication between students, which could be a problem in a collaborative learning settings, and differences in ontology might complicate communication between experts (teachers and professionals) and students (cf. Bromme, Rambow, \& Nückles, 2001). 


\section{References}

Anderson, R. C., Reynolds, R.E., Schallert, D. L., \& Goetz, E. T. (1977). Frameworks for comprehending discourse. American Educational Research Journal, 14, 367-381.

Ashley, K. D., \& Aleven, V. (1991). Toward an intelligent tutoring system for teaching law students to argue with cases. Proceedings of the Third International Conference on Artificial Intelligence and Law (pp. 42-52). New York: ACM press.

Ashley, K. D., \& Brüninghaus, S. (2003). A predictive role for intermediate legal concepts. In D. Bourcier (Ed.), Proceedings of The $16^{\text {th }}$ Annual Conference on Legal Knowledge and Information Systems (pp. 1-10). Amsterdam, The Netherlands: IOS Press.

Bench-Capon, T. J. M., \& Visser, P. R. S. (1997). Ontologies in legal information systems: The need for explicit specifications of domain conceptualisations. Proceedings of the Sixth International Conference on Artificial Intelligence and Law (pp.132-141). New York: ACM press.

Boon, P. J., Reijntjes, J. M., \& Rinkes, J. G. J. (2003). Inleiding tot de studie van het Nederlandse recht [Introduction to the study of Dutch law]. Deventer: Kluwer

Boshuizen, H. P. A., \& Schmidt, H. G. (1992). On the role of biomedical knowledge in clinical reasoning by experts, intermediates and novices. Cognitive Science, 16, 153-184.

Boshuizen, H. P. A., \& Schmidt, H.G. (2000). The development of clinical reasoning expertise. In J. Higgs \& M. Jones (Eds.), Clinical reasoning in the health professions (pp.15-22). Oxford: Butterworth Heinemann.

Bromme, R., Rambow, R., \& Nückles, M. (2001). Expertise and estimating what other people know: The influence of professional experience and type of knowledge. Journal of Experimental Psychology: Applied, 7, 317-330. 
Chi, M. T. H. (1997). Creativity : Shifting across ontological categories flexibly. In T. B. Ward, S. M. Smith, \& J. Vaid (Eds.), Creative thought: An investigation of conceptual structures and processes (pp. 209-234). Washington, DC: American Psychological Association.

Chi, M. T. H. (2005). Commonsense conceptions of emergent processes : Why some misconceptions are robust. The Journal of the Learning Sciences, 14, 161-199.

Chi, M. T. H., Glaser, R., \& Farr, M. J. (Eds.). (1988). The nature of expertise. Hillsdale, NJ: Erlbaum.

Chi, M. T. H., \& Roscoe, R. D. (2002). The processes and challenges of conceptual change. In M. Limón, \& L. Mason (Eds), Reconsidering Conceptual Change. Issues in Theory and Practice (pp. 3-27). The Netherlands: Kluwer Academic.

Crombag, H. F. M., de Wijkersloot, J. L., \& Cohen, M. J. (1977). Een theorie over rechterlijke beslissingen [A theory of judicial decisions]. Groningen, The Netherlands: H. D. Tjeenk Willink.

De Jong, T., \& Ferguson-Hessler, M. G. M. (1986). Cognitive structures of good and poor novice problem solvers in physics. Journal of Educational Psychology, 78, 279-288.

Dufresne, R. J., Gerace, W. J., Thibodeau-Hardiman, P., \& Mestre, J. P. (1992). Constraining novices to perform expertlike problem analysis: Effects on schema acquisition. The Journal of the Learning Sciences, 2, 307-331.

Elstein, A. S. (2001). Naturalistic decision making and clinical judgement. Journal of behavioral decision making, 14, 363-364.

Ericsson, K. A., Charness, N., Feltovich, P. J., \& Hoffman, R. R. (Eds.). (2006). The Cambridge Handbook of Expertise and Expert Performance. Cambridge MA: Cambridge University Press. 
Ericsson, K.A., \& Simon, H. A. (1993). Protocol analysis: Verbal reports as data (Rev. ed.). Cambridge, MA: MIT Press.

Hunt, E. (2006). Expertise, talent, and social encouragement. In K. A. Ericsson, N. Charness, P. J. Feltovich, \& R. R. Hoffman (Eds.), The Cambridge handbook of expertise and expert performance (pp.31-38). Cambridge MA: Cambridge University Press.

Kalyuga, S. (2006). Assessment of learners' organised knowledge structures in adaptive learning environments. Applied Cognitive Psychology, 20, 333-342.

Kelly, M. H., \& Keil, F. C. (1985). The more thing change...: Metamorphoses and conceptual structure. Cognitive Science, 9, 403-416.

Klausmeister, H. J. (1990). Conceptualizing. In B. F. Jones, \& L. Idol (Eds.), Dimensions of Thinking and Cognitive Instruction (pp. 93-138). Hillsdale, NJ: Erlbaum.

Klomp, R. J. Q., \& Mak, C. (2005). Burgerlijk Wetboek 2005/2006 [Civil Code 2005/2006]. Nijmegen: Ars Aequi Libri.

Lindahl, L. (2003). Operative and justificatory grounds in legal argumentation. Associations, 7 , $185-200$.

Lindahl, L. (2004). Deduction and justification in the law: The role of legal terms and concepts. Ratio Juris, 17, 182-202.

Nievelstein, F., Van Gog, T., \& Prins, F. J. (in press). Instructional models in domains and professions -Learning law: The problems with ontology and reasoning. In J. M. Spector, M. D. Merrill, J. J. G. Van Merriënboer, \& M. P. Driscoll (Eds.), Handbook of Research on Educational Communications and Technology (3rd ed.). Hillsdale, NJ: Erlbaum.

Roth, K. J. (1990). Developing meaningful conceptual understanding in science. In B. F. Jones, \& L. Idol (Eds.), Dimensions of Thinking and Cognitive Instruction (pp. 139 - 175). Hillsdale, NJ: Erlbaum. 
Schank, R., \& Abelson, R. A. (1977). Scripts, plans, goals and understanding: An inquiry into human knowledge structures. Hillsdale, NJ: Erlbaum.

Sullivan, M. W., Colby, A., Welch-Wegner, J., Bond, L., \& Shulman, L. S. (2007). Educating lawyers. San Francisco: Jossey-Bass.

Thagard, P. (1992). Adversarial problem solving: Modeling an opponent using explanatory coherence. Cognitive Sciene, 16, 123-149.

Trochim, W. M. K. (1989). An introduction to concept mapping for planning and evaluation. Evaluation and Program Planning, 12, 1-16.

Van de Wiel, M. W. J., Boshuizen, H. P. A., \& Schmidt, H. G. (2000). Knowledge restructuring in expertise development: Evidence from pathophysiological representations of clinical cases by students and physicians. European Journal of Cognitive Psychology, 12(3), 323355.

Van de Wiel, M. W. J., Boshuizen, H. P. A., Schmidt, H. G., \& Schaper, N. C. (1999). The explanation of clinical concepts by expert physicians, clerks, and advanced students. Teaching \& Learning in Medicine, 11, 153-163.

Van Gog, T., Paas, F., Van Merriënboer, J. J. G., \& Witte, P. (2005). Uncovering the problemsolving process: Cued retrospective reporting versus concurrent and retrospective reporting. Journal of Experimental Psychology: Applied, 11, 237-244.

Van Someren, M. W., Bernard, Y. F., \& Sandberg, J. A. C. (1994). The think aloud method: A practical guide to modeling cognitive processes. London: Academic Press.

Visser, P. R. S., \& Bench-Capon, T. J. M. (1998). A comparison of four ontologies for the design of legal knowledge systems. Artificial Intelligence and Law, 6, 27-57. 


\section{Appendix}

The coding scheme of the concept elaboration task

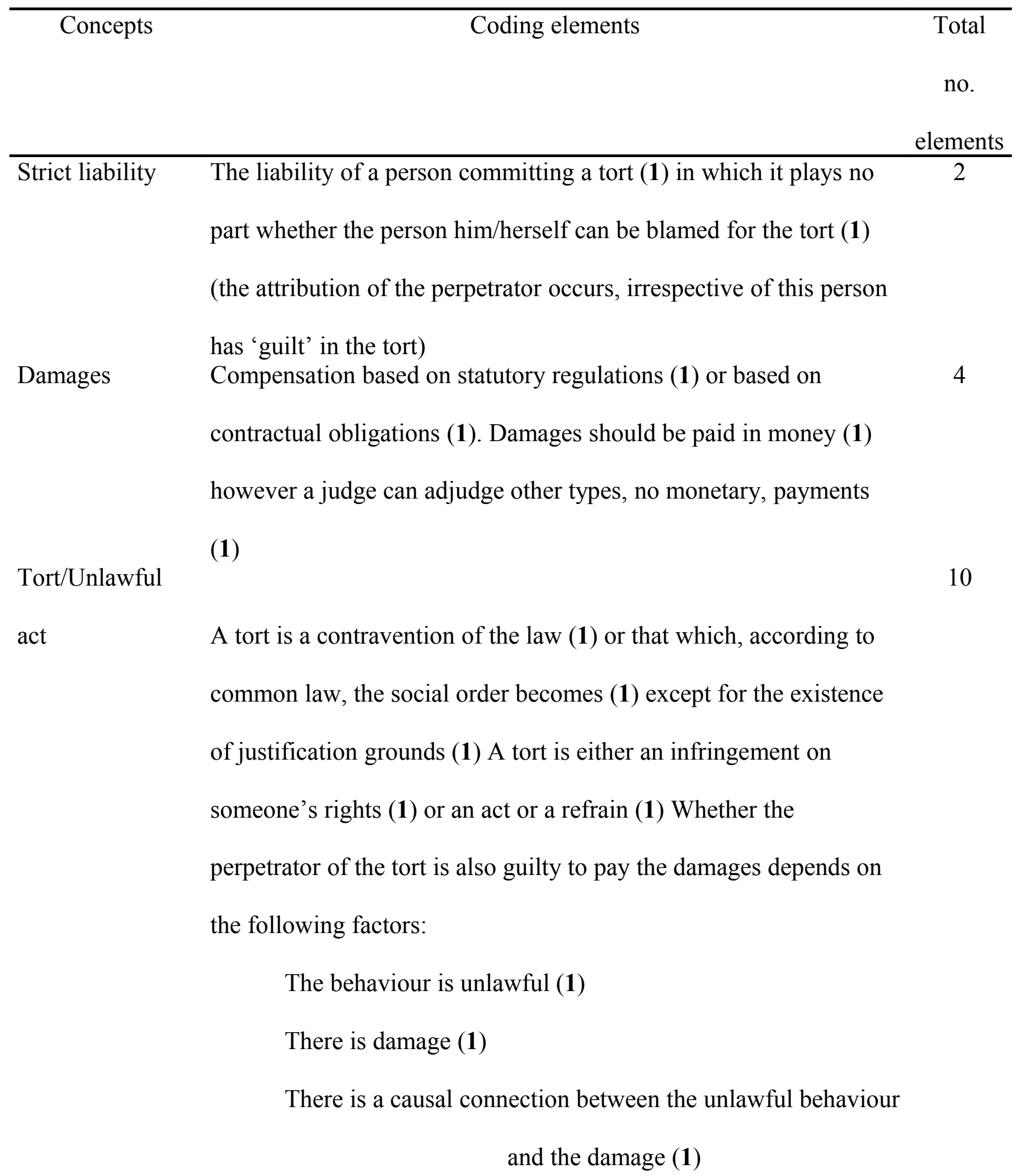


The unlawful behaviour can be ascribed to the perpetrator

Relativity and violated standard (1)

Protective norm There is no obligation to pay damages in the case the violated standard does not reach to protect against the damage the injured party has suffered (1)

Owner Ownership is the most including right an owner has regarding an object (1)

Examples regarding type 1, type 2 and type 3 examples of the concept elaboration task

\begin{tabular}{l}
\hline Examples \\
\hline Type 1 \\
a) 'strict liability': "Strict liability is for example if you know that if you lend your \\
bike to someone and this person falls on the street as a result of which (s)he dies." \\
b) damages': "For example if someone threatens you with a gun and you cannot sleep \\
anymore, you can claim damages." \\
Type 2 'tort': "If I remember correctly, it is something about the Cohen judgement, with \\
that false employee..." \\
b) 'protective norm "Well I remember an example about a judgement concerning the \\
pollution of a pond. As a result of this pollution a restaurant nearby had fewer \\
visitors. The question was whether this restaurant was protected by the protective \\
norm for it's damages." \\
a) 'tort': "A tort is a so-called out of contractual obligation. There are a few \\
situational constraints that point at the presence of a tort: There should be material \\
damage or personal harm, there has to be guilt and causality..." \\
b) 'strict liability': "For damage, harmed to a third party, through a mistake by a \\
subordinate (employee). The employer is responsible if (s)he created a certain risk to
\end{tabular}


Table 1

Means for the Type of Card Sort Methods per Group

\begin{tabular}{|c|c|c|c|c|c|c|}
\hline \multirow[b]{2}{*}{ Method } & \multicolumn{2}{|c|}{ Novices } & \multicolumn{2}{|c|}{ Advanced stud. } & \multicolumn{2}{|c|}{ Experts } \\
\hline & $M$ & $S D$ & $M$ & $S D$ & $M$ & $S D$ \\
\hline Central concepts & $2.12^{\mathrm{E}}$ & 1.08 & $2.71^{\mathrm{E}}$ & 1.27 & $4.50^{\mathrm{N}, \mathrm{A}}$ & 2.43 \\
\hline Random order & $5.17^{\mathrm{E}, \mathrm{A}}$ & 2.85 & $2.63^{\mathrm{N}}$ & 2.08 & $1.50^{\mathrm{N}}$ & 1.38 \\
\hline Fields of law & $0.00^{\mathrm{E}}$ & 0.00 & $0.17^{\mathrm{E}}$ & 0.48 & $2.17^{\mathrm{N}, \mathrm{A}}$ & 1.47 \\
\hline Top concepts & $0.00^{\mathrm{E}}$ & 0.00 & $0.08^{\mathrm{E}}$ & 0.28 & $0.50^{\mathrm{N}, \mathrm{A}}$ & 0.67 \\
\hline
\end{tabular}


${ }^{\mathrm{N}, \mathrm{A}, \mathrm{E}}$ In post-hoc multiple comparisons (after ANOVA, $p<.05$ ) significantly different from Novices, Advanced students and Experts. 
Table 2

Means for the Accurately Defined Elements per Group

\begin{tabular}{|c|c|c|c|c|c|c|}
\hline \multirow[b]{2}{*}{ Concepts } & \multicolumn{2}{|c|}{ Novices } & \multicolumn{2}{|c|}{ Advanced Stud. } & \multicolumn{2}{|c|}{ Experts } \\
\hline & $M$ & $S D$ & $\bar{M}$ & $S D$ & $M$ & $S D$ \\
\hline Strict liability & $0.25^{\mathrm{E}}$ & 0.44 & $0.38^{\mathrm{E}}$ & 0.49 & $1.17^{\mathrm{N}, \mathrm{A}}$ & 0.72 \\
\hline \multicolumn{7}{|l|}{ (central) } \\
\hline Damages (central) & 0.37 & 0.77 & $0.17^{\mathrm{E}}$ & 0.38 & $0.92^{\mathrm{A}}$ & 1.31 \\
\hline Tort/Unlawful act & $4.13^{\mathrm{A}}$ & 2.32 & $2.63^{\mathrm{N}, \mathrm{E}}$ & 1.37 & $4.58^{\mathrm{A}}$ & 1.08 \\
\hline \multicolumn{7}{|l|}{ (central) } \\
\hline Protective norm & $0.38^{\mathrm{E}}$ & 0.50 & $0.17^{\mathrm{E}}$ & 0.38 & $1.00^{\mathrm{N}, \mathrm{A}}$ & 0.00 \\
\hline \multicolumn{7}{|l|}{ (abstract) } \\
\hline Owner (intermediate) & $0.25^{\mathrm{A}, \mathrm{E}}$ & 0.44 & $0.71^{\mathrm{N}}$ & 0.46 & $1.00^{\mathrm{N}}$ & 0.00 \\
\hline Total & $5.38^{\mathrm{E}}$ & 2.84 & $4.00^{\mathrm{E}}$ & 1.56 & $8.58^{\mathrm{N}, \mathrm{A}}$ & 1.93 \\
\hline
\end{tabular}

$\mathrm{N}, \mathrm{A}, \mathrm{E}$ In post-hoc multiple comparisons (after ANOVA, $p<.05$ ) significantly different from

Novices, Advanced students and Experts. 
Table 3

Means for the Types of Examples Given per Concept per Group: Daily examples not related to the lawbook (Type 1), judicial examples not related to elements of the lawbook (Type 2), and judicial examples related to elements of the lawbook (Type 3).

\begin{tabular}{|c|c|c|c|c|c|c|c|c|c|c|c|c|c|c|c|c|c|c|}
\hline \multirow{4}{*}{$\begin{array}{l}\text { Concepts } \\
\text { Strict liability }\end{array}$} & \multicolumn{6}{|c|}{ Novices } & \multicolumn{6}{|c|}{ Advanced Stud. } & \multicolumn{6}{|c|}{ Experts } \\
\hline & \multicolumn{2}{|c|}{ Typel } & \multicolumn{2}{|c|}{ Type 2} & \multicolumn{2}{|c|}{ Type 3} & \multicolumn{2}{|c|}{ Type 1} & \multicolumn{2}{|c|}{ Type 2} & \multicolumn{2}{|c|}{ Type 3} & \multicolumn{2}{|c|}{ Type 1} & \multicolumn{2}{|c|}{ Type 2} & \multicolumn{2}{|c|}{ Type 3} \\
\hline & $M$ & $S D$ & $M$ & $S D$ & $M$ & $S D$ & $M$ & $S D$ & $M$ & $S D$ & $M$ & $S D$ & $M$ & $S D$ & $M$ & $S D$ & $M$ & $S D$ \\
\hline & $2.62^{\mathrm{A}, \mathrm{E}}$ & 1.28 & 0.08 & 0.28 & $1.42^{\mathrm{E}}$ & 1.47 & $1.00^{\mathrm{N}, \mathrm{E}}$ & 0.89 & 0.00 & 0.00 & 2.38 & 1.95 & $0.00^{\mathrm{N}, \mathrm{A}}$ & 0.00 & 0.00 & 0.00 & $3.00^{\mathrm{N}}$ & 1.65 \\
\hline (central) & & & & & & & & & & & & & & & & & & \\
\hline Damages & $2.42^{\mathrm{A}, \mathrm{E}}$ & 1.66 & 0.13 & 0.34 & $1.00^{\mathrm{A}, \mathrm{E}}$ & 0.59 & $0.04^{\mathrm{N}}$ & 0.20 & 0.04 & 0.20 & $1.67^{\mathrm{N}}$ & 0.76 & $0.17^{\mathrm{N}}$ & 0.39 & 0.00 & 0.00 & $2.01^{\mathrm{N}}$ & 1.38 \\
\hline (central) & & & & & & & & & & & & & & & & & & \\
\hline Tort/Unlawful & $2.54^{\mathrm{A}, \mathrm{E}}$ & 1.06 & 0.08 & 0.28 & $0.96^{\mathrm{E}}$ & 0.81 & $2.00^{\mathrm{N}, \mathrm{E}}$ & 0.72 & 0.00 & 0.00 & 0.83 & 0.96 & $0.50^{\mathrm{N}, \mathrm{A}}$ & 0.52 & 0.00 & 0.00 & $1.50^{\mathrm{N}}$ & 1.51 \\
\hline act (central) & & & & & & & & & & & & & & & & & & \\
\hline Protective norm & $1.92^{\mathrm{A}, \mathrm{E}}$ & 0.93 & 0.13 & 0.34 & $0.13^{\mathrm{A}, \mathrm{E}}$ & 0.34 & $0.00^{\mathrm{N}}$ & 0.00 & 0.04 & 0.20 & $0.96^{\mathrm{N}}$ & 0.75 & $0.25^{\mathrm{N}}$ & 0.62 & 0.00 & 0.00 & $0.67^{\mathrm{N}}$ & 0.65 \\
\hline (abstract) & & & & & & & & & & & & & & & & & & \\
\hline Owner & $2.00^{\mathrm{A}, \mathrm{E}}$ & 0.93 & 0.08 & 0.28 & $0.50^{\mathrm{E}}$ & 0.83 & $0.00^{\mathrm{N}}$ & 0.00 & 0.00 & 0.00 & $0.96^{\mathrm{E}}$ & 0.69 & $0.00^{\mathrm{N}}$ & 0.00 & 0.00 & 0.00 & $3.50^{\mathrm{N}, \mathrm{A}}$ & 1.17 \\
\hline (intermediate) & & & & & & & & & & & & & & & & & & \\
\hline Total & $11.54^{\mathrm{A}, \mathrm{E}}$ & 2.15 & $0.50^{\mathrm{A}, \mathrm{E}}$ & 0.66 & $4.00^{\mathrm{A}, \mathrm{E}}$ & 1.77 & $3.08^{\mathrm{N}, \mathrm{E}}$ & 1.35 & $0.08^{\mathrm{N}}$ & 0.28 & $6.79^{\mathrm{N}, \mathrm{E}}$ & 2.52 & $0.92^{\mathrm{N}, \mathrm{A}}$ & 0.90 & $0.00^{\mathrm{N}}$ & 000 & $10.42^{\mathrm{N}, \mathrm{A}}$ & 4.67 \\
\hline
\end{tabular}




\section{Figure Captions}

Figure 1. Novices' dendrogram

Figure 2. Advanced students' dendrogram

Figure 3. Experts' dendrogram 
Emotional damage

Injury

Protective norm

Damages

Monetary comp.

Penalty payment

Reinstatement

Rectification

Causality

Imputation

Protective norm

Infringement

Tort/unlawful act

Equity

Carefulness

Subjective right

Liability

Strict liability

Nuisance

Default

Obligation

Error

Owner

Ownership

Object

Depository

Bona fide

Expiration

Exculpation

Burden of proof

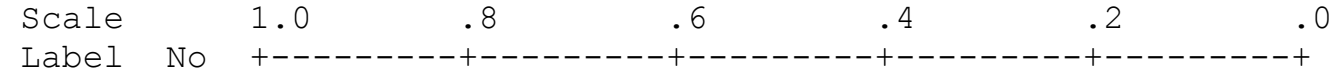

$$
\begin{aligned}
& 12 \square \square \square \\
& 14 \quad \square \quad \square \quad \square \\
& 19 \quad \square \quad \square \square \quad \text { 四 } \\
& 20 \quad \square \square \square
\end{aligned}
$$

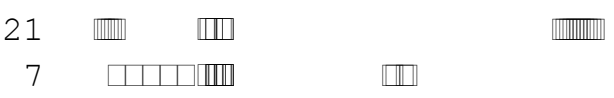

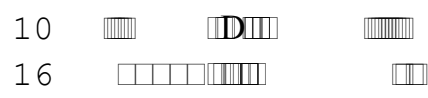

$$
\begin{aligned}
& 5 \quad \square \quad \square \quad \square \\
& \square \square \quad \square \\
& \text { 血 } \quad \square \square m \text { 四 } \quad \square
\end{aligned}
$$

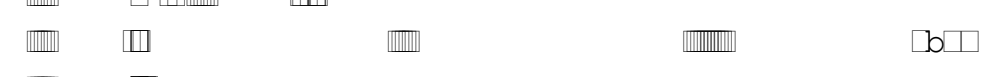

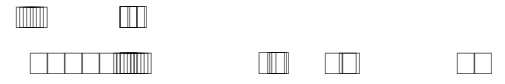

$$
\begin{aligned}
& \square \Pi \square[\| \square \square \square \square
\end{aligned}
$$

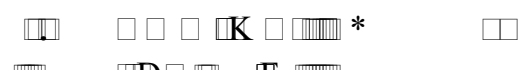

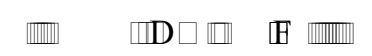

$$
\begin{aligned}
& \text { 西 } \square \\
& \text { 西 } \quad \square \quad \mathbb{N} \| \square \square
\end{aligned}
$$

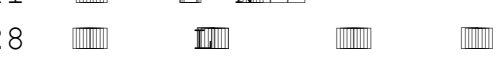

$$
\begin{aligned}
& 25 \square \mathbb{N} \square \square
\end{aligned}
$$

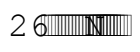

$$
\begin{aligned}
& 8 \quad \text { 而 }
\end{aligned}
$$

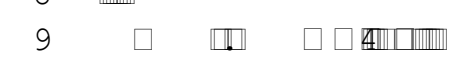

$$
\begin{aligned}
& 29 \quad \square \quad \square \quad \square
\end{aligned}
$$

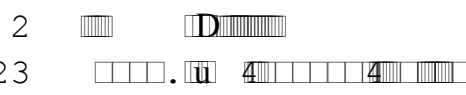

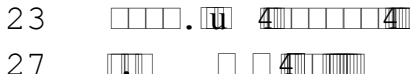

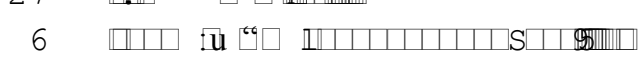




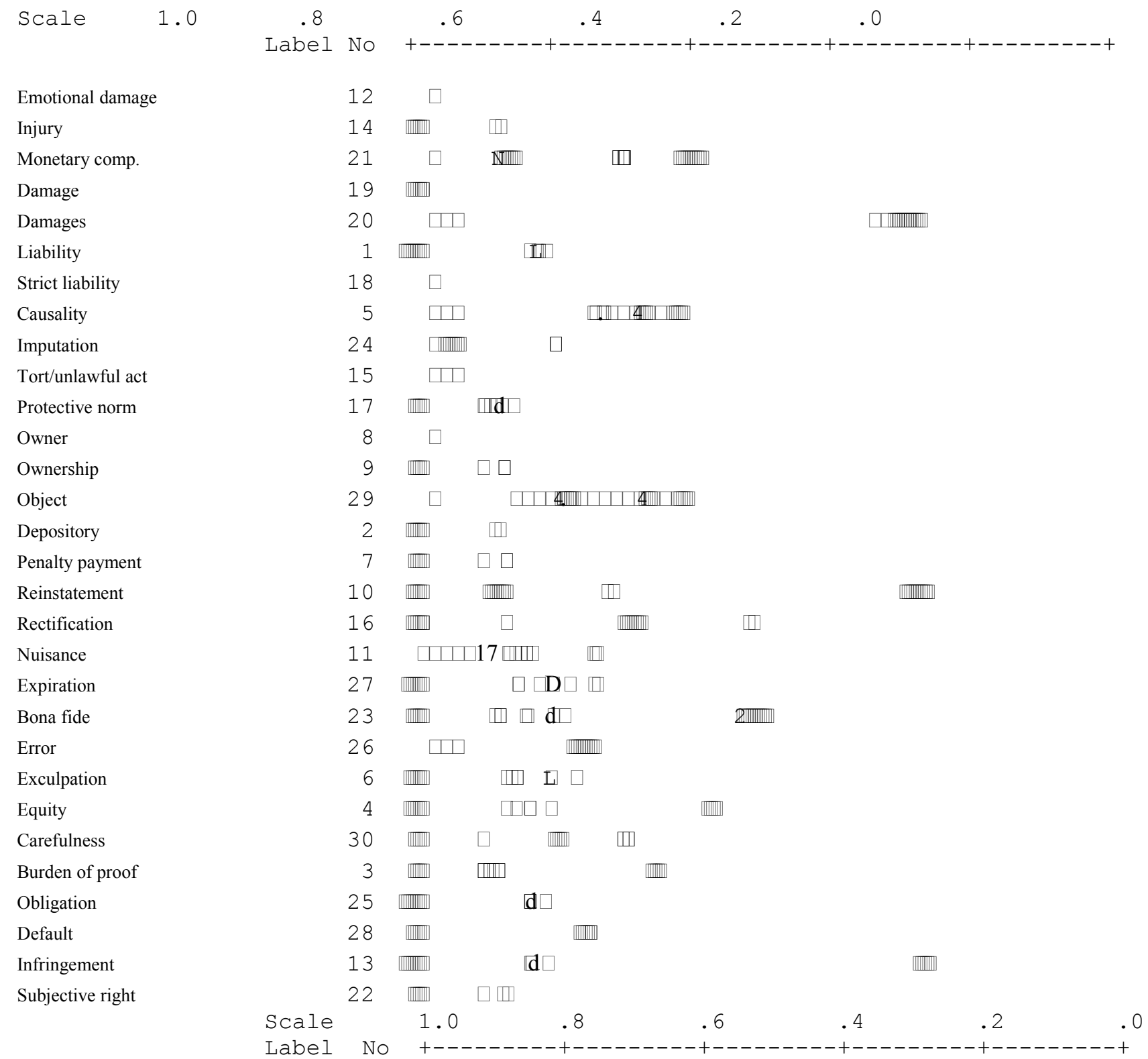

Emotional damages 
Monetary comp.

Injury

Protective

Carefulness

Infringement

Tort/unlawful act

Nuisance

Causality

Damage

Damages

Strict liability

Imputation

Liability

Reinstatement

Rectification

Penalty payment

Burden of proof

Damages

Owner

Ownership

Object

Depository

Bona fide

Error

Expiration

Obligation

Default

Equity

Subjective right
21 diा

14

17 四

$30 \quad \square \quad$ 血
13

15

$11 \quad \mathbb{m} \quad \mathbb{m}$

$5 \quad$ 而 $\square$

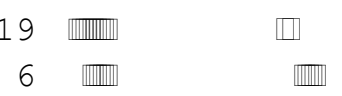

而盂

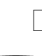

$\begin{array}{rr}1 & \text { 典 } \\ 10 & \text { m }\end{array}$

16

$7 \quad \mathbb{1}$

3 而

$\square \quad$ 罝 $\quad$ 晸

$\mathrm{C} \square$

孟 $\square$

2 而向

23 而

26 Iس

27 四

25 血

$28 \square$

$4 \quad$ 血

22 而血

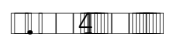

[पा山

$\mathrm{A} \square \square \square \square$

|

孟盂

d 